\title{
Study on the Influence Mechanism and Function of Accounting Environment on Accountants' Professional Ethics Education
}

\author{
Jinhua $\mathrm{Ha}^{1}$ \\ Harbin University of Commerce
}

\author{
$\mathrm{XuChen}{ }^{2}$ \\ Harbin University of Commerce
}

\begin{abstract}
The normal operation of the capital market is inseparable from the high-quality accounting information; accountants' professional ethics education behavior has impacted some investors' confidence in the capital market. The higher pressure, supervision and ethical development level have always influenced the accounting practice. This paper studies the accountants' professional ethics from the angle of accounting environment, and puts forward some measures to improve the accountants' professional ethics. The results show that the work environment factors such as superior pressure and supervision are taken into account when the accountants make the decision of ethics education behavior. The experimental results show that the ethics strength has little influence on the professional ethics intention of the accountants, but the interaction among the superior pressure, the supervision and the level of ethical development affects the occurrence of the intention of accountants' professional ethics. The research in this paper provides the experimental and theoretical basis for the study of accountants' professional ethics.
\end{abstract}

\section{Keywords}

Accounting Information • Accountants’ Professional Ethics • Accounting Environment • Superior Pressure • Supervision

${ }^{1}$ Correspondence to: Jinhua $\mathrm{Ha}(\mathrm{PhD})$, School of Accounting, Harbin University of Commerce, Harbin 150028, China. Email: hajinhua@126.com

${ }^{2}$ School of Accounting, Harbin University of Commerce, Harbin 150028, China. Email: 1722718169@qq.com

Citation: Ha, J. H., \& Chen, X., Study on the Influence Mechanism and Function of Accounting Environment on Accountants' Professional Ethics Education. Educational Sciences: Theory \& Practice, 18(5), 2438-2446. http://dx.doi.org/10.12738/estp.2018.1.0608 
Accounting information is the performance table that an enterprise presents to the public and the majority of shareholders, and the quality of accounting information directly affects the normal operation of the capital market (Tormo-Carbó, Seguí-Mas \& Oltra, 2016). In order to obtain high quality accounting information, accountants must be able to make right professional judgment. Accountants' professional judgment is based on solid accounting professional level and good accountants' professional ethics (Jha, Mclean, Gibbs \& Sandars, 2014). Accounting is a long-term focus of attention. In order to comply with the Accounting Standards for Business Enterprises, accountants as the enterprise's administrative personnel, are subject to command and influence from a superior leader in practical work (Fiolleau, Kaplan, Greenwood \& Freeman, 2017). The ethical situation mainly includes ethical violators, problem type and intensity, victims, etc. In the actual work, the accountants don't have supervision, and under the pressure from their superior leaders, some accountants act against the interests of the shareholders of the enterprise (Cameron, 2015).

Accountants' professional ethics involves many subjects, such as accounting, psychology, and statistics Accountants' professional ethics belongs to the category of individual ethics decision-making, and professional ethics reasoning is a process in which individuals use logics to judge the right or wrong things in the case of individual decision-making (Martinovbennie \& Mladenovic, 2015; Nakar, Bagnall \& Hodge, 2018).

Professional ethics can be divided into three stages: Kohlberg's Theory of Moral Development Stage, Rest's Four-component Model of Ethical Decision-making (including moral recognition, moral judgment, moral intention and moral behavior) and Jones's Theory of Moral Strength (Bobek, Hageman \& Radtke, 2015). From the perspective of game theory, the issue of accountants' professional ethics is the lack of accountants' integrity, accounting environment has an important impact on accountants' professional ethics, which is subject to changes in the workplace and cognitive psychology of people (Sinieliaskas, Bewley, Gronewold \& Menzefricke, 2016). This paper analyzes the accountants' professional ethics based on the accounting environment, analyzes the interaction effect among all influencing factors, and puts forward the measures to improve the accountants' professional ethics.

\section{Current Situation and Situation Development of the Dilemma of Accountants' Professional Ethics}

The accounting in enterprises or government institutions is as important as the economy, and accounting information has become the focus of leadership attention (Mahdavikhou \& Khotanlou, 2012). In the functional system, the accountants belong to the subordinates, and the accounting working environment directly affects the accountants' professional ethics (Gunz \& Thorne, 2017). When a leader wants to complete a certain performance appraisal, he will try to put pressure on the accountants, during which the accountants also will face the ethical dilemma. Accountants' professional ethics is caused by accounting activities, and has the characteristics of occupation, universality, self-discipline, heteronomy, inheritance and practicality. 
Table 1

Government or Business Survey on The Importance of Accountants' Professional Ethics

\begin{tabular}{lcc}
\hline Reply & Sample number & Percentage \\
\hline Very concerned & 25 & $9.03 \%$ \\
Pay more attention & 97 & $35.02 \%$ \\
A little attention & 51 & $18.41 \%$ \\
Uncertain & 37 & $13.36 \%$ \\
A little disregard & 47 & $16.97 \%$ \\
Less attention & 15 & $5.42 \%$ \\
Not paying much attention & 5 & $1.81 \%$ \\
Total & 277 & $100 \%$ \\
\hline
\end{tabular}

In this section, the current situation of accountants' professional ethics dilemma is investigated, and 277 valid questionnaires are collected. More than 70\% respondents think accountants' professional ethics is very important, and more than $40 \%$ think accountants' professional ethics needs to be improved. Table 1 is a questionnaire on the attention paid to accountants' professional ethics by the government or enterprises and more than $25 \%$ respondents believe that the government or enterprises lack supervision and norms on accountants' professional ethics. Table 2 shows whether the accounting work environment is affected by the higher level, and $87.73 \%$ of the accounting workers are affected by the higher level.

Table 2

Whether the Accounting Work Environment is Subject to the Influence from the Superiors

\begin{tabular}{lcc}
\hline Reply & Sample number & Percentage \\
\hline Influential & 243 & $87.73 \%$ \\
Non-influenced & 34 & $12.27 \%$ \\
Total & 277 & $100 \%$ \\
\hline
\end{tabular}

\section{Analysis on the Function Mechanism of Accountants' Professional Ethics Education Behavior}

In the actual accounting environment, there are many behavioral factors affecting the ethics of the accounting staff, which can be roughly divided into four parts: ethical education behavior and ethical intention, personal factors, event factors, working environment factors and demographic variables, as shown in Figure 1. Among them, the working environment factors include the superior pressure and the supervision strength. With various orders put forward by the management to accountants, accountants will have the ethical inclination under the accounting ethics and the pressure, and are more inclined to carry out the ethical education behavior to the issues with greater ethical intensity, and otherwise to those with lower ethical intensity. However, there are great differences in ethical education behavior for accounting personnel of different companies, and accountants of large companies are more inclined to ethical education behavior. The common measurement model for the moral development of accountants is to determine the problem detection model, which divides the moral development of people into three levels and six stages, and each level and each stage have a corresponding score, i.e., the higher the score value is, the stronger the moral capacity of the individuals is. 


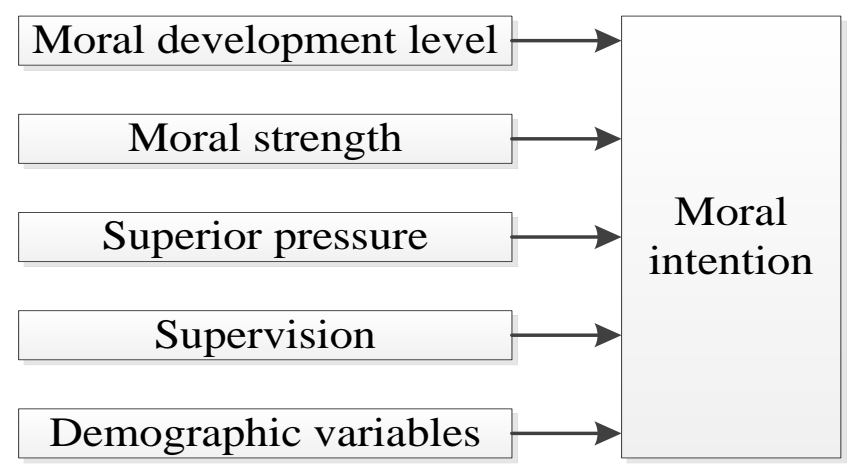

Figure 1. An ethical behavior model of accounting personnel based on accounting environment.

\section{Experimental Study on Ethics Education Behavior of Accountants}

\section{Experimental design}

The behavior and psychology of accountants cannot be obtained through accounting information. This experiment design mainly considers the influence of accounting working environment on the educational behavior of accountants' professional ethics. The event factors include moral intensity, superior pressure and supervision, with the problem score also tested as a variable. The pre-experiment is carried out before the experiment is started, and the statistical effectiveness of the experiment is estimated based on the pre-experiment information. Table 3 is the conventional effect value proposed by Cohen. In the field of professional ethics, the effect value is generally small or medium. Figure 2 shows the relationship between statistical effectiveness and the required sample size under unrelated samples, and it can be seen that when the effect value is small, the estimated sample size is about 190. Figure 3 is a structure diagram of a four-factor hybrid design experiment. This experiment is divided into two parts: distribute and collect the questionnaire for determining the problem score and distribute and collect follow-up questionnaire. When studying the impact of accounting environment on accountants' professional ethics, four groups of experimental conditions are set according to the superior pressure and the supervision strength, respectively, as shown in Table 4. The subjects all come from the personnel engaged in the accounting industry, and the data are analyzed by multi-factor analysis of variance to control the independent variables as much as possible so as to highlight the impact of the accounting environment.

Table 3

Conventional Effect Values Proposed by Cohen

\begin{tabular}{lc}
\hline Effect level & Effect value $\mathrm{f}$ \\
\hline Small & $\mathrm{f}=0.10$ \\
Medium & $\mathrm{f}=0.25$ \\
Large & $\mathrm{f}=0.40$ \\
\hline
\end{tabular}




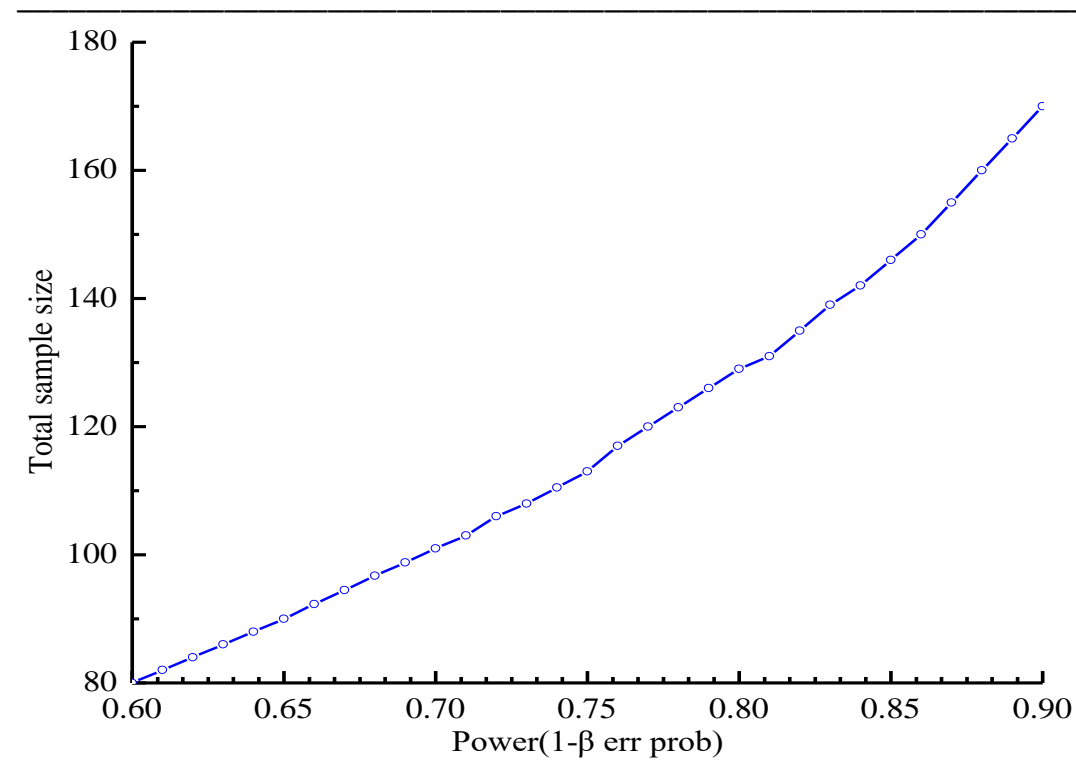

Figure 2. The relationship between statistical power and the required sample size under irrelevant samples.

Table 4

Experimental Conditions for Superior Pressure and Supervision

\begin{tabular}{lcc}
\hline \multirow{2}{*}{ Independent variable - supervision } & \multicolumn{2}{c}{ Independent variable - superior pressure } \\
\cline { 2 - 3 } & Level 1: Low pressure & Level 1: Strong pressure \\
\hline Level 1: Small supervision & Condition 1 & Condition 2 \\
Level 2: Strong supervision & Condition 3 & Condition 4 \\
\hline
\end{tabular}

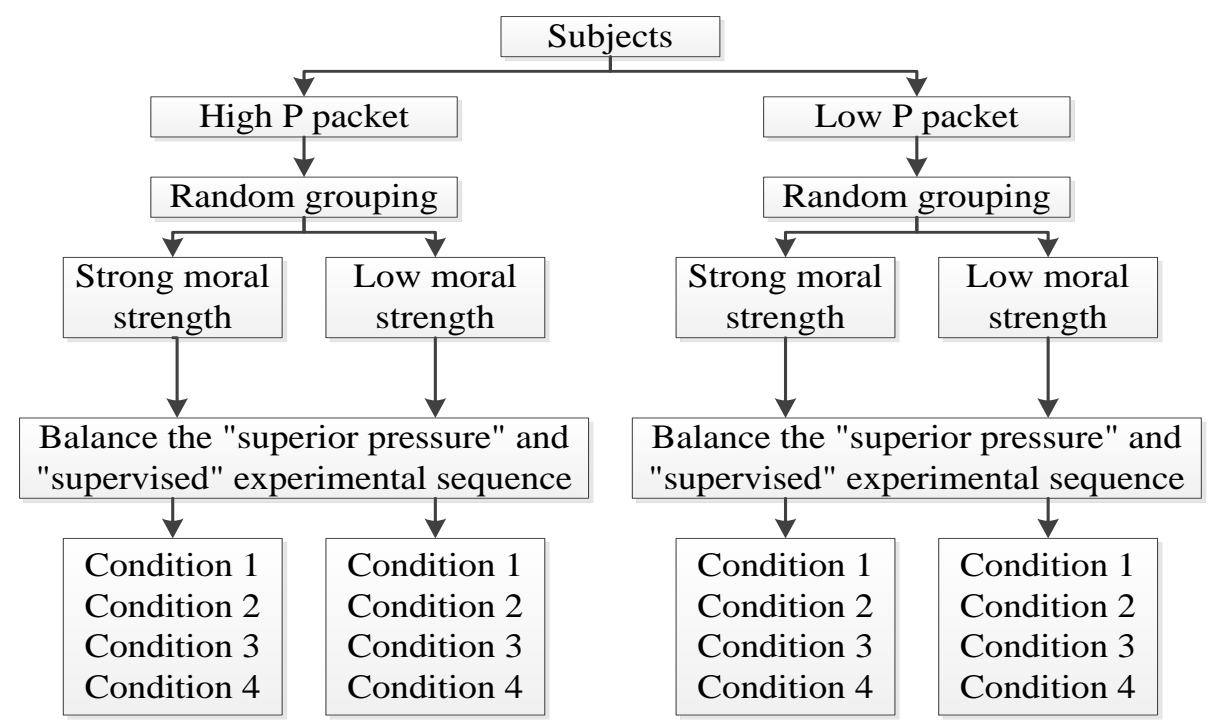

Figure 3. Four-factor hybrid design experimental structure. 
Ha, Chen / Study on the Influence Mechanism and Function of Accounting Environment on Accountants' Professional...

\section{Experimental results and analysis}

Table 5 is a descriptive statistical table of the research variables. The moral development level is expressed by specific numerical values, and the moral development level scores are grouped according to the median into P-score median (PHL). The descriptive statistical table of the research variables is shown in Table 6. The analysis of PHL shows that the intention of accounting personnel with high level of moral development is obviously higher than that of accounting personnel with low level of moral development. Figure 4 is a graph showing the interaction between the moral development level and the superior pressure, and the superior pressure and the moral development level have a significant influence on the accountants' professional ethics intention in the accounting environment. Figure 5 is a graph showing the interaction between superior pressure and supervision, which affects the occurrence of accountants' professional ethics. However, the research shows that the interaction between supervision and moral development level has no significant influence on accountants' professional ethics.

Table 5

Descriptive Statistics of Research Variables

\begin{tabular}{lccccc}
\hline Project & Sample number & Mean & S.D. & Min. & Max. \\
\hline Moral development level & 277 & 26.717 & 115819 & 4.3 & 59 \\
\hline
\end{tabular}

Table 6

Descriptive Statistics of Research Variables

\begin{tabular}{llccc}
\hline Project & Category & Sample number & Percentage & Cumulative percentage \\
\hline \multirow{3}{*}{ PHL } & Low & 125 & $46.5 \%$ & $46.5 \%$ \\
& Middle & 43 & $16.3 \%$ & $62 \%$ \\
\multirow{3}{*}{ Moral strength } & High & 107 & $40 \%$ & $100 \%$ \\
& Small & 138 & $48 \%$ & $48 \%$ \\
\multirow{2}{*}{ Superior pressure } & Big & 138 & $48 \%$ & $100 \%$ \\
& Small & 138 & $48 \%$ & $48 \%$ \\
Supervision & Big & 138 & $48 \%$ & $100 \%$ \\
& Small & 138 & $48 \%$ & $48 \%$ \\
& Big & 138 & $48 \%$ & $100 \%$ \\
\hline
\end{tabular}

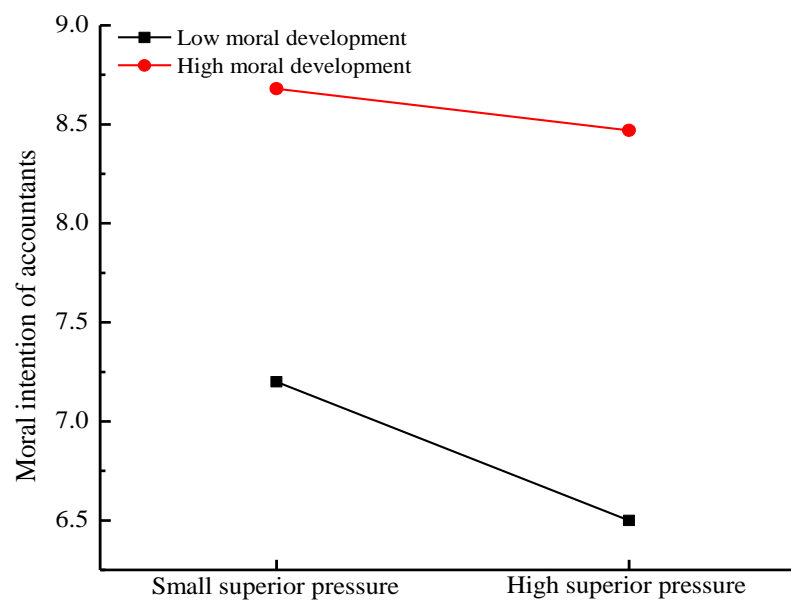

Figure 4. Interaction diagram between moral development level and superior pressure. 


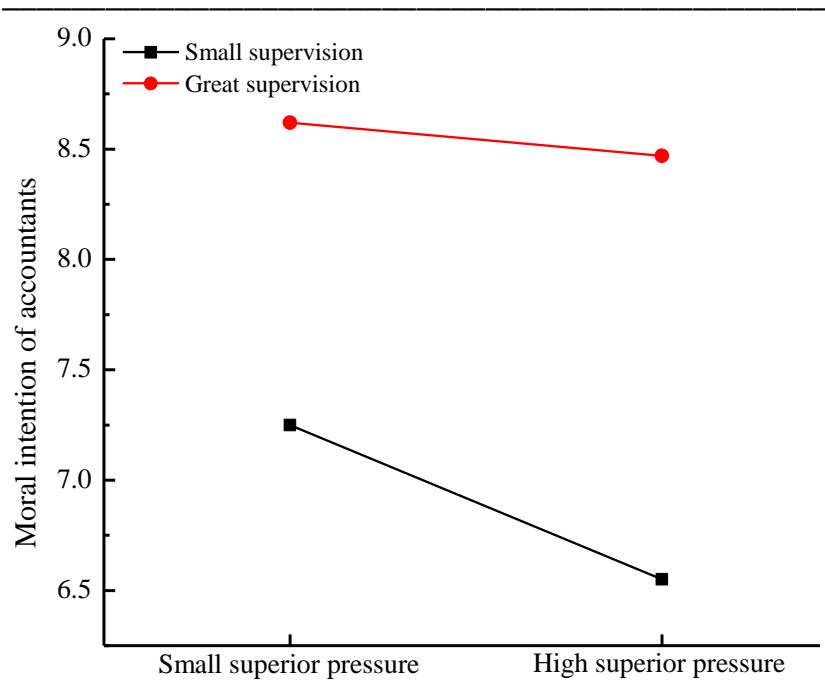

Figure 5. Interaction diagram between superior pressure and supervision.

\section{Measures to optimize the educational behavior of accountants' professional ethics}

To optimize the accountants' professional ethics, we should optimize the accounting environment and link the technical competence with the moral values. First, we should optimize the corporate governance structure, weaken the improper pressure from the superior, and improve the performance assessment method of the management so as to avoid the improper intervention of the superior to the accountants. To integrate the current supervision system and optimize the external environment of the moral education behavior of accountants, we should mainly restrict the accountants' ethics through the external and the internal supervision. To improve ethical literacy and enhance the immunity of accountants to resist non-moral education, we should integrate ethical literacy into the examination system of accountant appointment and dismissal, and train accountants with professional ethics on a regular basis, so as to construct a good organizational culture and form a reasonable atmosphere for accounting personnel to receive ethical education.

\section{Conclusion}

This paper studies the accountants' professional ethics from the angle of accounting environment, and puts forward some measures to improve the accountants' professional ethics. The concrete conclusions are as follows:

(1) Accountants' professional ethics is caused by accounting activities, and has the characteristics of occupation, universality, self-discipline, heteronomy, inheritance and practicality. The research shows that more than $70 \%$ respondents think accountants' professional ethics is very important, and more than $40 \%$ think accountants' professional ethics needs to be improved. 
Ha, Chen / Study on the Influence Mechanism and Function of Accounting Environment on Accountants' Professional...

(2) There are great differences in ethical education behavior for accounting personnel of different companies and strength events, and accountants of large companies are more inclined to ethical education behavior and to carry out the ethical education behavior to the issues with greater ethical intensity, and otherwise to those with lower ethical intensity.

(3) In the accounting environment, the superior pressure and the moral development level have a significant influence on the intention of accountants' professional ethics, and the interaction between the superior pressure and the supervision strength influences the intention of accountants' professional ethics. However, the interaction between the supervision and the moral development level has no significant effect on the intention of accountants' professional ethics.

\section{References}

Tormo-Carbó, G., Seguí-Mas, E., \& Oltra, V. (2016). Accounting ethics in unfriendly environments: The educational challenge. Journal of business ethics, 135(1), 161-175. http://dx.doi. org/10.1007/s10551-0142455-6

Jha, V., Mclean, M., Gibbs, T. J., \& Sandars, J. (2014). Medical professionalism across cultures: A challenge for medicine and medical education. Medical Teacher, 37(1), 74-80. http://dx.doi. org/10.3109/0142159X.2014.920492

Fiolleau, K., Kaplan, S. E., Greenwood, M., \& Freeman, R. E. (2017). Recognizing ethical issues: An examination of practicing industry accountants and accounting students. Journal of Business Ethics, 142(2), 259-276. http://dx.doi. org/10.1007/s10551-016-3154-2

Cameron R A C. (2015). Improving ethical attitudes or simply teaching ethical codes? the reality of accounting ethics education. Accounting Education, 24(4), 275-290. http://dx.doi. org/10.1080/09639284.2015.1036893

Martinovbennie, N., \& Mladenovic, R. (2015). Investigation of the impact of an ethical framework and an integrated ethics education on accounting students' ethical sensitivity and judgment. Journal of Business Ethics, 127(1), 189-203. http://dx.doi. org/10.1007/s10551-013-2007-5

Nakar, S., Bagnall, R. G., \& Hodge, S. (2018). A reflective account of the vet fee-help initiative as a driver of ethical dilemmas for vocational education teachers in Australia. Australian Educational Researcher, 45(3), 383-400. http://dx.doi. org/10.1007/s13384-018-0257-z

Bobek, D. D., Hageman, A. M., \& Radtke, R. R. (2015). The influence of roles and organizational fit on accounting professionals' perceptions of their firms' ethical environment. Journal of Business Ethics, 126(1), 125-141. http://dx.doi. org/10.1007/s10551-013-1996-4

Smieliauskas, W., Bewley, K., Gronewold, U., \& Menzefricke, U. (2016). Misleading forecasts in accounting estimates: a form of ethical blindness in accounting standards? Journal of Business Ethics, (1), 437-457. http://dx.doi. org/10.1007/s10551-016-3289-1

Mahdavikhou, M., \& Khotanlou, M. (2012). New approach to teaching of ethics in accounting: 'Introducing Islamic ethics into accounting education'. Procedia - Social and Behavioral Sciences, 46, 1318-1322. http://dx.doi. org/10.1016/j.sbspro.2012.05.294 
Ha, Chen / Study on the Influence Mechanism and Function of Accounting Environment on Accountants' Professional...

Gunz, S., \& Thorne, L. (2017). Introduction to thematic symposium on accounting professionalism. Journal of Business Ethics, 142(2), 199-201. http://dx.doi. org/10.1007/s10551-016-3147-1 